\title{
AVALIAÇÃO DE ACESSIBILIDADE EM ESCOLAS PÚBLICAS: ESTUDOS DE CASO EM DUAS ESCOLAS DE PASSO FUNDO-RS
}

\author{
ACCESSIBILITY ASSESSMENT IN PUBLIC SCHOOLS: A CASE STUDY IN TWO \\ SCHOOLS IN PASSO FUNDO-RS
}

Tales Gonçalves Visentin ${ }^{1}$, Bolsista PIBIC.

Marina Bernardes ${ }^{2}$, Arq.

Grace Tibério Cardoso ${ }^{3}$, Dra.

(1) Faculdade Meridional IMED

e-mail: tales.visentin@aiesec.net

(2) UFCS

e-mail: arq.marinabernardes@gmail.com

(3) Faculdade Meridional IMED

e-mail: grace.seixas@imed.edu.br

Palavras-chave: Acessibilidade, escola pública, inclusão social.

Este artigo apresenta um diagnóstico de acessibilidade nos espaços físicos internos e externos em duas escolas da rede pública na cidade de Passo Fundo - RS, através da Avaliação Pós Ocupação (APO), In loco técnica Walkthrough e aplicação de checklist. Os resultados evidenciaram as principais barreiras que impedem a locomoção independente, confortável e segura de pessoas com mobilidade reduzida, nos espaços públicos, interna e externamente aos ambientes educacionais, e demonstrou, a partir das análises, o que tem sido feito, servindo como modelo construtivo para futuras adaptações acessíveis nos espaços que mais necessitam de inclusão social e fluidez natural. Adaptações que irão contrastar com estruturas inadequadas atuais, percursos insalubres, bem como a discrepância de acessibilidade destes espaços em função do tempo em que foram construídos.

This article presents a diagnosis of accessibility in internal and external spaces in two schools of the public network in the city of Passo Fundo - RS, through the Post Occupational Assessment (APO), In loco, Walkthrough technique 
and checklist application. The results evidenced the main architectural barriers. The results evidenced the main barriers that prevent the independent, comfortable and safe transportation of people with reduced mobility in public spaces, internally and externally to the educational environments, and demonstrated, from the analysis, what has been done, serving as a constructive model For future adaptations accessible in spaces that most need social inclusion and natural fluidity. Adaptations that will contrast with current inadequate structures, unhealthy pathways, as well as the accessibility discrepancy of these spaces as a function of the time in which they were constructed.

\section{Introdução}

Existem no Brasil cerca de 45,6 milhões de pessoas com algum tipo de deficiência, contabilizando quase $24 \%$ da população brasileira, segundo o Censo do IBGE (2000). Desse total, 4,3\% são crianças de até 14 anos. A taxa de escolarização das crianças de 7 a 14 anos com deficiência é de $88,6 \%$, enquanto a taxa de 3 escolarização do total de crianças nesta faixa etária é de 94,5\% (IBGE, 2000). Em relação à Educação, somente a partir de 1996, é que o Brasil passou a ter avanços significativos, com a aprovação da "Lei de Diretrizes e Bases da Educação Nacional" (Lei ${ }^{\circ}$ 9.394), em que passou a ser obrigatória a inclusão de alunos com restrições, no que tange à acessibilidade e mobilidade, na rede de ensino regular, tornando necessária a adaptação espacial nos edifícios escolares a esses alunos. Atualmente, essas adaptações arquitetônicas são amparadas pela Lei ${ }^{\circ} 10098 / 2000$ e pelo Decreto Federal $n^{\circ}$ 5296/2004.

Segundo Evangelo (2014), para atender a estas exigências, as escolas deveriam adequar algumas de suas estruturas e espaços arquitetônicos. Embora os critérios para tornar os ambientes acessíveis pareçam bastante simples, a grande maioria das escolas não possui instalações adequadas para receberem os alunos. Segundo o mesmo autor, muitas pessoas com deficiência não podem ter acesso a todos os espaços e equipamentos da escola, porque são limitadas pelas barreiras arquitetônicas encontradas nos seus ambientes; tampouco, possuem recursos didáticos adequados aos tipos de deficiências existentes; nem mesmo para as mais comuns, como a cegueira e a surdez.

Com isso, Evangelo (2014) afirma que as escolas encontram grande dificuldade quando recebem um aluno que necessita dessas adaptações, fazendo com que este tenha um baixo rendimento na aprendizagem dos conteúdos ou até mesmo levando-o a desistir dos estudos.

A forma que municípios têm optado por aplicar os conceitos de acessibilidade e mobilidade nos edifícios de maneira global, não tem atendido os parâmetros estabelecidos pela Norma Brasileira 9050/2004, como a construção de no mínimo uma rota acessível nos ambientes e equipamentos e mobiliários adaptados, não atendendo as necessidades básicas das pessoas com deficiência e mobilidade reduzida.

Percebe-se, então, a necessidade de novas estratégias para tornar efetiva a aplicação dos mesmos. Também é notória a dificuldade que os governos municipais têm para cumprir as normas em todas as unidades (DISCHINGER et al. 2012).

Diante disso, este artigo tem como objetivo geral realizar um diagnóstico em duas escolas da rede pública de Passo Fundo - RS, identificando possíveis barreiras relacionadas à acessibilidade e mobilidade, utilizando escolas construídas em diferentes períodos, visando investigar como estas questões estão sendo implantadas em novos edifícios escolares. Espera-se os resultados deste trabalho possam colaborar para a qualificação de futuros espaços escolares e seus entornos imediatos, visando promover a igualdade de acesso a todos os usuários.

\section{Referencial teórico}

\subsection{Acessibilidade e ergonomia}

O tema da inclusão na área educativa ganhou força com a Declaração de Salamanca (1994), a qual
Realização:

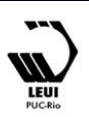




\section{$16^{\circ}$ \\ ERGODESIGN USIHC CINAHPA}

teve como objetivo inspirar o princípio de escola para todos, apoiando a aprendizagem que considera as diferenças. A Declaração afirma que cada criança possui suas características e capacidades, mas que todos os alunos devem ter acesso às escolas regulares, reconhecendo e satisfazendo as suas necessidades diversas, adaptando-se aos estilos e ritmos destes usuários. (CORDE, 1994.)

A acessibilidade é um atributo indispensável no ambiente e garante a melhoria na qualidade de vida das pessoas. Além disso, proporciona à pessoa com deficiência a possibilidade de viver de forma autônoma e segura, permitindo o seu acesso e garantindo igualdade com os demais. (CONADE, 2004).

$\mathrm{O}$ ambiente escolar influencia no processo de inclusão para o desenvolvimento das relações sociais. Diante disso, propor melhorias neste meio, irá refletir na construção de uma sociedade que considera a diversidade. (DE OLIVEIRA et.al, 2011).

A definição pela Associação Brasileira de Ergonomia, baseada na definição da Internacional Ergonomics Association, estabelece que a ergonomia é o estudo das interações das pessoas com o ambiente, e tem por objetivo intervir em projetos a fim de qualificar os espaços, com segurança e conforto, beneficiando as atividades humanas. (ABERGO, 2010).

Segundo Bins Ely (2003), a arquitetura e ergonomia podem possibilitar ambientes atrativos e funcionais, mas ressalta que os princípios de ergonomia devem ser inseridos durante o processo de projeto. Aplicando as ferramentas de ergonomia e acessibilidade é possível garantir espaços onde as pessoas não se sintam excluídas, seja uma instituição de ensino, na sua própria habitação ou em ambientes de lazer. (DA PRAIA, 2011).

\section{Procedimentos metodológicos}

A pesquisa é classificada como aplicada, do tipo exploratória e qualitativa, sendo o delineamento $16^{\circ}$ Ergodesign - Congresso Internacional de Ergonomia e Usabilidade de Interfaces Humano Tecnológica: Produto, Informações Ambientes Construídos e Transporte

$16^{\circ}$ USIHC - Congresso Internacional de Ergonomia e Usabilidade de Interfaces Humano Computador

CINAHPA | 2017 - Congresso Internacional de Ambientes Hipermídia para Aprendizagem. um estudo de caso. Este tipo de pesquisa tem como principal objetivo propor maior familiaridade com o problema, caracterizando-se pela sua linguagem acessível e simplicidade no procedimento. (GIL, 2010). Esta pesquisa está estruturada em três etapas, e teve como objeto de estudo duas escolas da rede pública de Passo Fundo - RS.

A primeira etapa foi realizada utilizando a avaliação in loco, baseada na técnica da Avaliação Pós-Ocupação (APO), executada através de levantamento fotográfico e medições, em conjunto com a análise das plantas baixas. A avaliação in loco não consiste apenas em observar e escrever, mas também em examinar fatos e fenômenos que se desejam estudar (MARCONI e LAKATOS, 1996).

A segunda etapa foi efetuada a aplicação de checklists desenvolvidos pelos pesquisadores, com o objetivo de avaliar itens da acessibilidade do espaço físico interno e do entorno imediato das escolas. Os checklists foram desenvolvidos utilizando a Norma Brasileira 9050/2004 e medições de Evangelo (2014), e Dischinger et al. (2012).

A terceira etapa consistiu na aplicação da metodologia Walkthrough, a qual tem como objetivo realizar um percurso dialogado, que abrange os ambientes complementados por fotografias e croquis, e assim, possibilita ao pesquisador a familiarização com o edifício (RHEIGANTZ, 2009). Os pesquisadores realizaram o percurso internamente e externamente as escolas selecionadas, anotando informações técnicas, medidas espaciais, e conversas com os usuários (alunos, professores, diretores). Com esse método foi possível avaliar as edificações do ponto de vista técnico-construtivo.

\section{Resultados e discussão}

\subsection{Estudo de caso}

As escolas escolhidas para análise foram construídas em períodos históricos distintos na cidade de Passo Fundo/RS, com diferentes conceitos de eficiência energética e acessibilidade.
Realização:

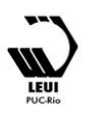




\section{$16^{\circ}$ \\ ERGODESIGN USIHC CINAHPA}

$16^{\circ}$ Ergodesign - Congresso Internacional de Ergonomia e Usabilidade de Interfaces Humano Tecnológica: Produto, Informações Ambientes Construídos e Transporte

$16^{\circ}$ USIHC - Congresso Internacional de Ergonomia e Usabilidade de Interfaces Humano Computador

CINAHPA | 2017 - Congresso Internacional de Ambientes Hipermídia para Aprendizagem.
A escola "Instituto Estadual Cecy Leite Costa" foi inaugurada em junho de 1965, tendo mais de 50 anos de atuação em Passo Fundo-RS. Trata-se de uma escola pública estadual, de fomento ao ensino médio e alguns cursos técnicos, possui 3

pavimentos, tendo o segundo e terceiro pavimentos do bloco principal destinados a práticas

educacionais. Este bloco possui 14 salas de aulas e capacidade para atender 420 alunos por turno do ensino médio, com alunos entre 14 a 18 anos.

(Figura 01 a).

A Escola Modelo Vila Luíza, foi inaugurada em no final de 2016, e com previsão de início das aulas em abril de 2017, possui 2 andares, 11 salas de aula, com capacidade de atender 330 alunos por turno, com idades até 6 anos. Segundo os arquitetos responsáveis, foi projetada para ser a maior escola de educação infantil do município, com o objetivo de inserir novos elementos, e estratégias de arquitetura sustentável, como a captação e reuso de águas, placas fotovoltaicas, brises e preocupação com a iluminação natural. (Figura 01 b).
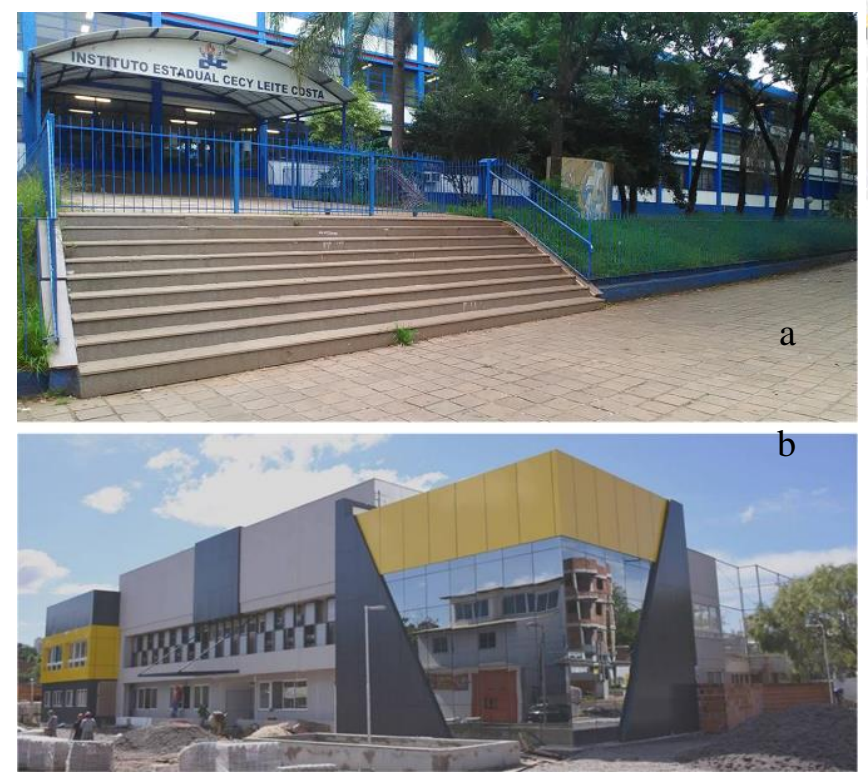

Figura 1: Fachada das escolas Cecy Leite Costa e Fonte: Autores, 2017.

4.2 Avaliação e medições externas
Para o percurso externo foram identificados e representados na figura 2 a localização das escolas na malha urbana da cidade, e os percursos/caminhos predominantes de acesso às escolas, levando em consideração que parte significativa dos alunos/professores/funcionários, utilizam o transporte coletivo para chegar na escola. Portanto, para traçar o percurso e avaliar a mobilidade do entorno foram considerados os itens: a) acesso às escolas, b) passeio público, c) travessias de ruas, faixas e rampas d) paradas de ônibus mais próximas.

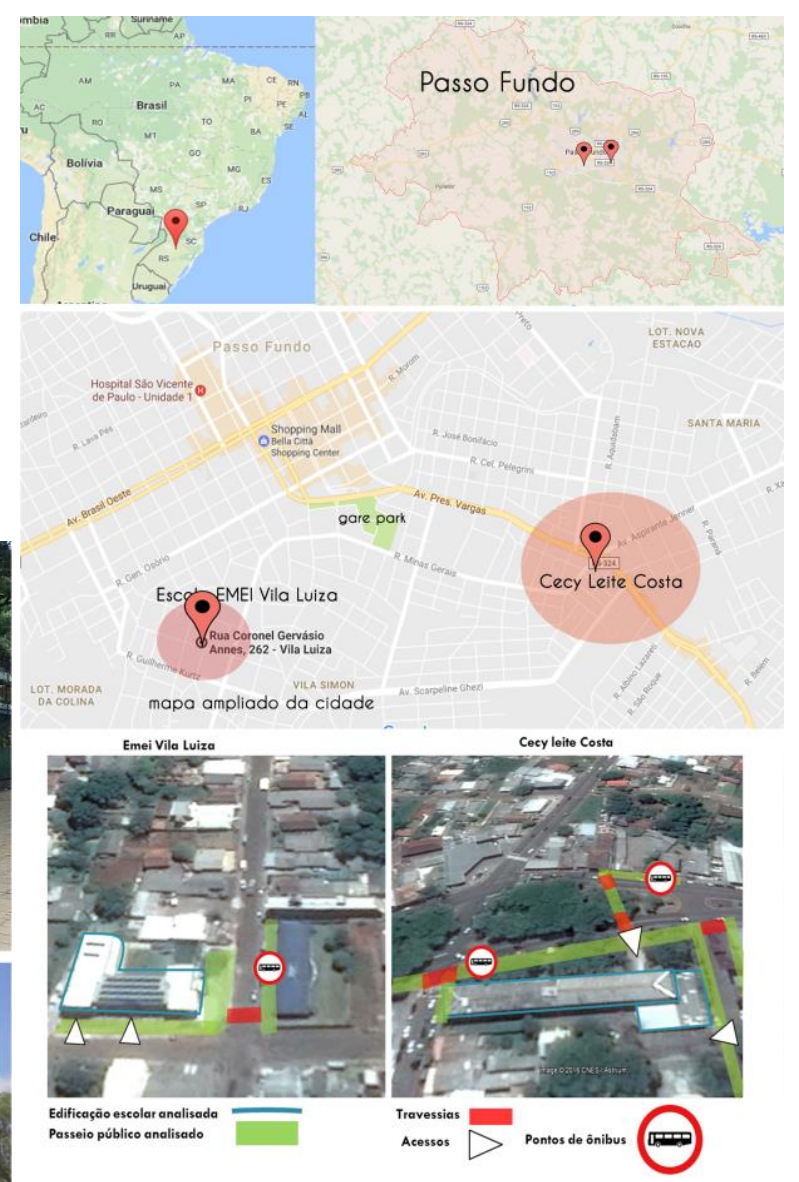

Figura 2: Análise e medições externas Fonte: Autores, 2017

Ao observar as imagens acima, bem como, vivenciar o espaço in loco, são notáveis as diferenças de desnível e de localização na malha urbana da cidade, onde se encontram as duas escolas. A Escola Modelo (Figura 03) está situada em um bairro afastado do centro, em um lote plano
Realização:

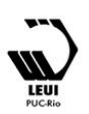




\section{$16^{\circ}$ \\ ERGODESIGN USIHC CINAHPA}

$16^{\circ}$ Ergodesign - Congresso Internacional de Ergonomia e Usabilidade de Interfaces Humano Tecnológica: Produto, Informações Ambientes Construídos e Transporte

$16^{\circ}$ USIHC - Congresso Internacional de Ergonomia e Usabilidade de Interfaces Humano Computador

CINAHPA | 2017 - Congresso Internacional de Ambientes Hipermídia para Aprendizagem. em relação à rua e o passeio público, favorecendo a acessibilidade. Não existem desníveis do passeio público à escola e as rampas são sutis entre a rua e a calçada, como pode ser observado na figura 3 , além disso, há piso tátil no entorno do passeio. Ou seja, a estrutura e dimensão do espaço público onde diariamente alunos, professores e funcionários farão seu percurso de entrada/saída da escola, garantem melhores condições de caminhabilidade no entorno imediato à escola.

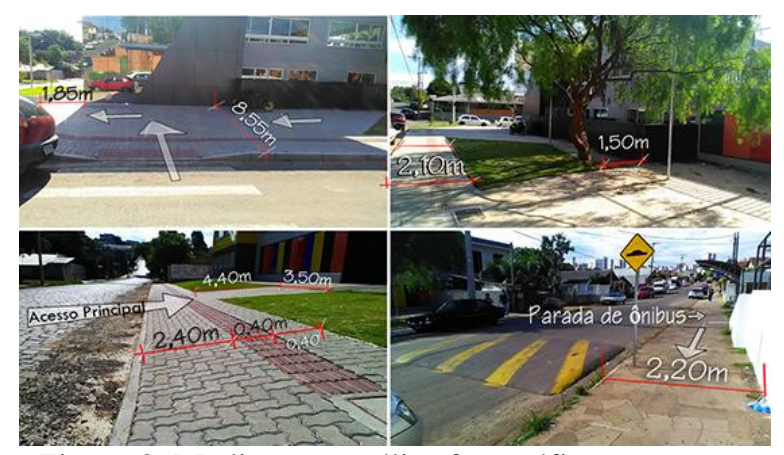

Figura 3: Medições e análise fotográfica externa na escola Modelo da Vila Luiza.

Fonte: Autores, 2017.

Nas imediações da escola, há um posto de saúde, o qual intensifica o fluxo veicular e de pedestres na região. Diante disso, recomenda-se a inserção de sinalizações de alerta aos motoristas

Já na escola Cecy Leite Costa (Figura 04), é evidente outra realidade histórica em questões de mobilidade urbana, pois está situada na Avenida Presidente Vargas, uma via arterial, com $2 \mathrm{~km}$ de extensão a partir do centro da cidade, e interliga Passo Fundo com a RS-324, possibilitando o acesso à cidade de outros municípios. Assim, esta via possui intensa circulação diária de automóveis, sendo mais de mil automóveis por hora em horários de pico, (KUNZ et al. 2016).

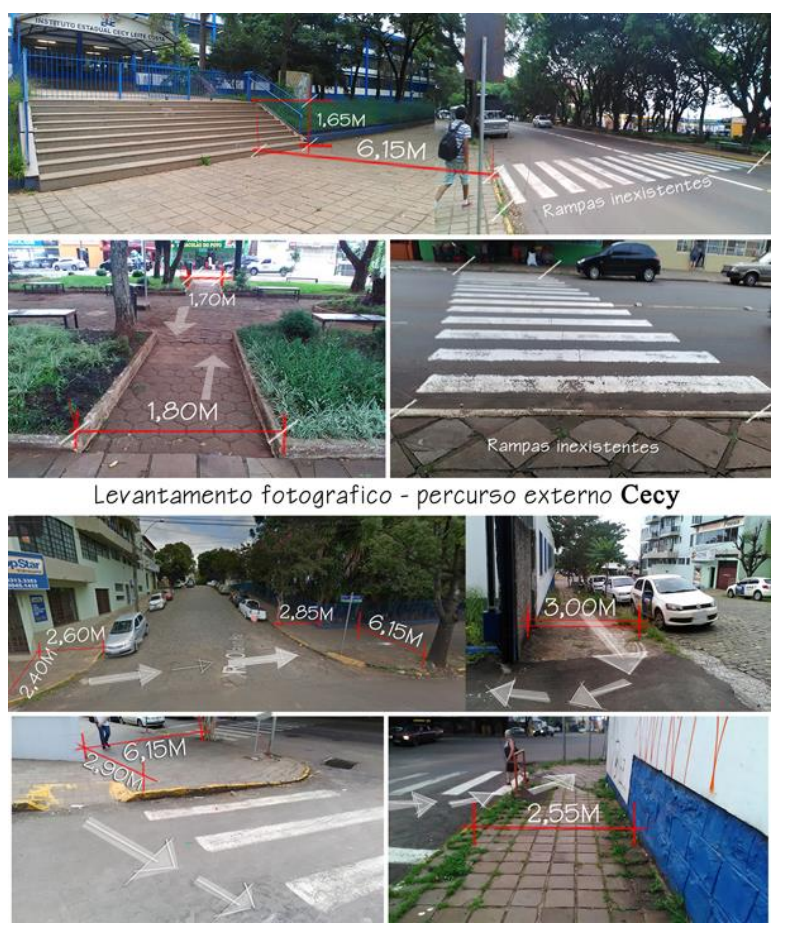

Figura 4: Medições e análise fotográfica externa na escola Cecy Leite Costa.

Fonte: Autores, 2017.

\subsection{Avaliação e medições internas}

Além dos itens externos citados e avaliados para o exterior imediato das duas escolas, foram analisados os espaços físicos internos, bem como o preenchimento do checklist, baseado na norma 9050 (2004), e também por meio do levantamento fotográfico, medições e pesquisas bibliográficas, foram escolhidos itens relevantes que, em desacordo com normas de acessibilidade, se tornam barreiras para a inclusão escolar. Considerando o ambiente interno, os espaços físicos considerados foram: a) corredores (circulação horizontal), b) circulação vertical (escadas, rampas elevador).

Na figura 5, observam-se os espaços internos avaliados e suas dimensões espaciais, salientando que, as escolas estudos de caso deste artigo, atendem demandas diferentes de alunos, enquanto escola Cecy Leite Costa (Figura 5 a), possui 3 pavimentos, sendo o segundo e terceiro destinados para atividades educacionais, com 14 salas de aula
Realização:

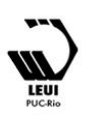




\section{$16^{\circ}$ \\ ERGODESIGN USIHC CINAHPA}

e capacidade para atender 420 alunos por turno, do ensino médio, englobando alunos de 14 a 18 anos, a Escola Modelo Vila Luíza (Figura 5 b), possui 2 andares, 11 salas de aula, com capacidade de atender 330 alunos por turno, de até 6 anos, a
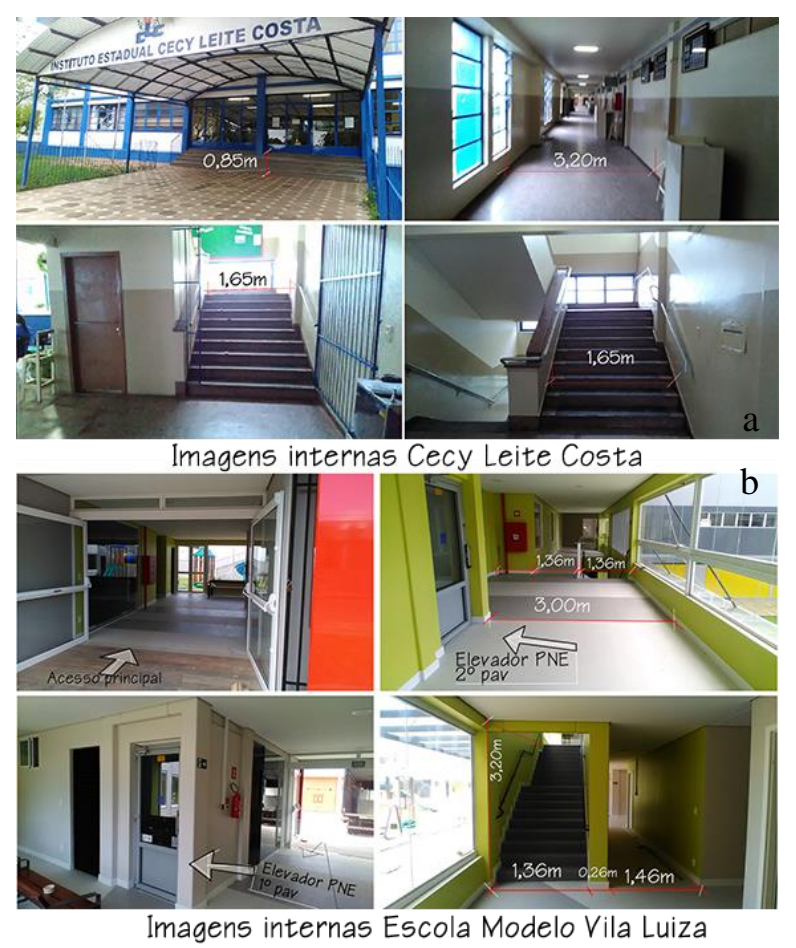

Figura 5: análise e medições internas Fonte: Autores, 2017.

A NBR 9050 (2004) relaciona informações normativas e exigências gerais para as escolas, mas não existem exigências específicas para os ambientes escolares como as salas de aula ou laboratórios. Resumidamente, os parâmetros estabelecidos sobre a estrutura e dimensões espaciais necessárias para um fluxo saudável e acolhedor de pessoas nos ambientes escolares, estão distribuídos ao longo da norma. Por conta disso, foram extraídas as principais exigências que permeiam seus espaços físicos para a elaboração do checklist, sendo estruturados para que se assinalassem as seguintes opções:

1. Atende - Quando o sub-item verificado em campo estava de acordo com a normas vigente. $16^{\circ}$ Ergodesign - Congresso Internacional de Ergonomia e Usabilidade de Interfaces Humano Tecnológica: Produto, Informações Ambientes Construídos e Transporte

$16^{\circ}$ USIHC - Congresso Internacional de Ergonomia e Usabilidade de Interfaces Humano Computador

CINAHPA | 2017 - Congresso Internacional de Ambientes Hipermídia para Aprendizagem.

Os itens analisados nos ambientes, segundo o checklist elaborado de acordo com a norma NBR 9050 (2004), foram: Entrada e saída, corredores (circulação horizontal), circulação vertical (rampa), e circulação vertical (escada). Cada um dos itens possui atributos para serem avaliados. Estes atributos possuem suas exigências construtivas relacionadas às dimensões, ao formato/forma, à textura, ao local de instalação, etc. (2012).

Durante o percurso walkthrough, ao perceber espacialmente os ambientes externos e internos in loco, foram observados alguns obstáculos, que dificultam a vida de pessoas com deficiência ou mobilidade reduzida. No passeio público próximo, travessias que impossibilitam um cadeirante de circular sem ajuda, há falta de rampas acessíveis no entorno e internamente na escola Cecy, que possui escadas apenas, como também um elevador que poderia conectar o primeiro pavimento aos $2^{\circ} \mathrm{e}$ $3^{\circ}$, tornando o ambiente escolar totalmente acessível.

São observações que serão levadas em consideração no seguimento do projeto de pesquisa que está em desenvolvimento, onde serão criadas proposições arquitetônicas que visarão à sustentabilidade, ergonomia e economia de energia.

Evidenciou-se na escola Modelo Vila Luiza, a implantação de tecnologias verdes, soluções que irão economizar energia e desenvolver a consciência ecológica dos usuários. Além disso, a escola apresentou soluções acessíveis, espaços seguros e amplos para o aprendizado, nos espaços internos e entorno imediato, porém nas quadras ao lado, e na rua, foram observados problemas estruturais, como a falta de asfaltamento, e pavimentação irregular nas calçadas das imediações.

Realização:

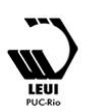




\section{$16^{\circ}$ \\ ERGODESIGN USIHC CINAHPA}

Os passeios públicos que interligam as escolas com os pontos de ônibus e quarteirões próximos, apesar de sua estrutura e tipologia serem visualmente inadequadas, em contraponto, possuem dimensão adequada para comportar sua demanda diária, pequenos detalhes nos espaços públicos, como as rampas de ligação da rua com o passeio, nas proximidades da escola Cecy causam um enorme problema de mobilidade, por estarem em más condições para um caminhar seguro e confortável, em desacordo com as normas e faixas de travessia desalinhadas com o passeio público.

\section{Conclusão}

A partir deste diagnóstico, pode-se identificar as principais barreiras associadas à acessibilidade $\mathrm{e}$ mobilidade nas escolas estudadas. A realidade da maioria das escolas públicas estaduais e municipais que foram construídas e/ou projetadas no período da escola estadual Cecy Leite Costa por exemplo, com mais de 50 anos de atuação, enfrentam as dificuldades de inclusão em função da falta de preocupação com a acessibilidade. $16^{\circ}$ Ergodesign - Congresso Internacional de Ergonomia e Usabilidade de Interfaces Humano Tecnológica: Produto, Informações Ambientes Construídos e Transporte

$16^{\circ}$ USIHC - Congresso Internacional de Ergonomia e Usabilidade de Interfaces Humano Computador

CINAHPA | 2017 - Congresso Internacional de Ambientes Hipermídia para Aprendizagem.
No caso da escola Modelo Vila Luiza, inaugurada em 2016, percebe-se o contraste em seu espaço físico, já que a mesma foi implantada em terreno plano e possui aplicada em seu edifício, maior facilidade de acesso com rampas e elevador, além disso, foram implantadas tecnologias inovadoras e sustentáveis, como por exemplo os painéis fotovoltaicos e o reaproveitamento das águas pluviais.

Os resultados levantados neste trabalho estão servindo de base técnica e teórica para futuras pesquisas em espaços educacionais e ações de empreendedorismo, onde serão desenvolvidos projetos de readequações acessíveis e ambientais, em obras públicas, escolares, como também, propondo soluções para problemas urbanos atuais, em parcerias com o poder público e privado, tendo objetivos de fomentar o mercado construtivo sustentável na região e incentivar a melhoria e novos olhares ecológicos sobre os espaços educacionais no Brasil.

\section{BIBLIOGRAFIA}

ABERGO - Associação Brasileira de Ergonomia. Disponível em: < http://www.abergo.org.br/> . Acesso em: 18, janeiro. 2017.

\begin{abstract}
ABRAHÃO, J.; SZNELWAR, L.; SILVINO, A.; SARMET, M.; PINHO, D. Introdução à ergonomia: da prática à teoria. São Paulo, Blucher, 2009.
\end{abstract}

ASSOCIAÇÃO BRASILEIRA DE NORMAS TÉCNICAS. NBR 9050: Acessibilidade a Edificações, Mobiliário, Espaços e Equipamentos Urbanos. Rio de Janeiro, 2004.

BRASIL. Lei n. 8.213. Dispõe sobre os Planos de Benefícios da Previdência Social e dá outras providências. Brasília: DOU, 1991.

CONADE. Conselho Nacional dos Direitos da Pessoa Portadora de Deficiência. Brasília: CONADE, 2004.

CORDE. Declaração de Salamanca e linha de ação sobre necessidades educativas especiais. 


\section{$16^{\circ}$ \\ ERGODESIGN USIHC CINAHPA}

$16^{\circ}$ Ergodesign - Congresso Internacional de Ergonomia e Usabilidade de Interfaces Humano Tecnológica: Produto, Informações Ambientes Construídos e Transporte

$16^{\circ}$ USIHC - Congresso Internacional de Ergonomia e Usabilidade de Interfaces Humano Computador

CINAHPA | 2017 - Congresso Internacional de Ambientes Hipermídia para Aprendizagem.
Brasília: CORDE, 1994.

GIL, A.C. Como elaborar projetos de pesquisa. São Paulo. $5^{\circ}$ Ed. Editora: Atlas. 2010.

DA PRAIA, Campus Universitário da Cidade; GRANDE, Palmarejo; VERDE, Santiago Cabo. Ergonomia e Acessibilidade, 2011.

DE OLIVEIRA BORDIGNON, K.K; CANAN, S.R; PIOVESAN, J. Acessibilidade arquitetônica nas escolas municipais de frederico westphalen para educandos com deficiência física: Limites e Possibilidades da Inclusão. Revista Contexto \& Saúde, 2013.

DISCHINGER, M; BINS ELY, V H. M. Promovendo acessibilidade nos edifícios públicos: Guia de avaliação e implementação de normas técnicas. Santa Catarina: Ministério Público do Estado, 2005.

ELY, B. I. N. S.; ERGONOMIA, V. Arquitetura: buscando um melhor desempenho do ambiente físico. Anais do $3^{\circ}$. Ergodesign- $3^{\circ}$. In: Congresso Internacional de Ergonomia e Usabilidade de interfaces humano-tecnologia: Produtos, programa, informação, ambiente construído. Rio de Janeiro. LEUI/PUC-Rio. 2003.

RHEINGANTZ, P.A et al. Observando a qualidade do lugar: procedimentos para a avaliação pósocupação. Rio de Janeiro: Proarq| FAU-UFRJ, 2009.

MARCONI, M. de A.; LAKATOS, E. M.. Técnicas de pesquisa: planejamento e execução de pesquisas, amostragens e técnicas de pesquisas, elaboração, análise e interpretação de dados. 3 ed. Atlas. São Paulo, 1996.

EVANGELO, Larissa Silva. Avaliação da acessibilidade e mobilidade arquitetônica em escolas de ensino fundamental de viçosa MG. 2014. 174 f. Dissertação (Mestrado) - Curso de Arquitetura e Urbanismo, Universidade Federal de Viçosa, Viçosa, 2014.

DISCHINGER, Marta et al (Org.). Promovendo acessibilidade espacial nos edifícios públicos: Programa de Acessibilidade às Pessoas com Deficiência ou Mobilidade Reduzida nas Edificações de Uso Público. Santa Catarina: Ministério Público do Estado de Santa Catarina, 2012. $161 \mathrm{p}$.

KUNZ, M. et al. Projeção e Estratificação Quantitativa de Circulação de Unidades Veiculares na Cidade de Passo Fundo (RS), Brasil: Proporção e Análise. Impacto Científico e Social na Pesquisa, Passo Fundo, p.12-19, 2016. Complexo de Ensino Superior Meridional S.A.. http://dx.doi.org/10.18256/978-85-99924-83-9-2.

Realização:

